E3S Web of Conferences 1, 12002 (2013)

DOI: $10.1051 / \mathrm{e} 3$ sconf/20130112002

(c) Owned by the authors, published by EDP Sciences, 2013

\title{
Effect of diet on the capacity to remove mercury from the body of a penguin (Spheniscus demersus) living in the ZOO
}

\author{
L. Falkowska ${ }^{1}$, E. Szumiło $^{1}$, J. Hajdryh $^{1}$, A. Grajewska ${ }^{1}$, M. Bełdowska ${ }^{1}$ and I. Krause ${ }^{2}$ \\ ${ }^{1}$ Institute of Oceanography, Department of Marine Chemistry and Environmental Protection, University of Gdansk A1. \\ M.Piłsudskiego 46,81-378 Gdynia, Poland, lucynafalkowska@gmail.com; emiszu@gmail.com; \\ ${ }^{2}$ Municipal Zoological Garden, Karwieńska 3, 80-001 Gdańsk, Poland
}

\begin{abstract}
Birds due to its position in the trophic chain are good monitors of the marine environment in terms of mercury contamination. For the proper interpretation of results it is necessary to know both the processes of accumulation of this metal in their bodies and processes of elimination. Research involving the Penguin (Spheniscus demersus) living in a ZOO has identified the relationship between diet and the amount of mercury removed from the penguin body in guano, feathers, and in the case of females with eggs. The research was conducted in years 2009-2011. Total mercury was determined in elements responsible for detoxification and in the diet of penguins. Mercury concentration was determined by atomic absorption spectrophotometry with AMA-254 automatic mercury analyzer. The highest average mercury concentrations were determined in feathers: $1781.12 \mathrm{ngHg} \mathrm{g}^{-1}$ d.w., lower in eggs: $950.88 \mathrm{ngHg}^{\circ} \mathrm{g}^{-1}$ dry weight (d.w.). and in a guano: 139.18 $\mathrm{ngHg} \cdot \mathrm{g}^{-1}$. In food, herrings caught in the southern Baltic, $\mathrm{Hg}$ concentrations were relatively low with averaged value $31.81 \mathrm{ngHg} \bullet \mathrm{g}^{-1} \mathrm{~d} . \mathrm{w}$.
\end{abstract}

Key words: total mercury, Spheniscus demersus, detoxification, feathers, guano, egg

\section{Introduction}

Mercury is one of the most toxic elements present in the aquatic ecosystem and its impact on living organisms dependent on the chemical form of its occurrence. The most dangerous are organic mercury compounds which are not only highly toxic but also undergo bioaccumulation and biomagnifications - a crucial processes in ecotoxicology. All these factors impel to systematic control of the level of mercury and its compounds in the environment. It is well known that the birds due to its position in the tropic chain are good monitors of the marine environment in terms of mercury contamination. Mercury concentration in tissues and organs of birds is closely bond to diet, because food ingestion is main route by which this metal enters the organism. Mercury is absorbed from air and water in minor way and level of this element in the body of birds is a result of accumulation and detoxification process depended on the specific character of species and geographical factors. In this study African penguins (Spheniscus demersus) living in Gdańsk ZoologicalGarden "Wybrzeża" was tested. Their diet include herring (Clupea herengus) caught in the Polish Economic
Zone of Baltic Sea. Penguins ate $0.5 \mathrm{~kg}$ of fish daily. $\mathrm{ZOO}$ as an environment controlled by human provides a lot of information that receiving in nature would be very difficult. The aim of this study was to investigate the effect of homogeneous diet on processes of mercury removal from the body of penguin.

\section{Material and Methods}

All elements responsible for the detoxification of the penguin (guano, feathers, eggs) and both with their food (fish) were analyzed. Feathers were collected throughout the year from June to July 2010 year, then washed in 50 $\%$ acetone and dried for $24 \mathrm{~h}$ at $25{ }^{\circ} \mathrm{C}$. Eggs were collected after breeding season. If it was possible the albumen was separated from the yolk and shell from parchment membrane. Albumen and yolk after freezedrying were homogenized. Schell was washed in $50 \%$ acetone and dried with parchment membrane at $25^{\circ} \mathrm{C}$ for $24 \mathrm{~h}$. For a half of a year once a month penguin guano was collected using a glass filter and then freeze-dried. From the whole mass of Baltic herring (Clupea harengus) periodically delivered to the ZOO, 3 or 4 fish were randomly selected every month for a year. Selected fish 


\section{E3S Web of Conferences}

were homogenized and freeze-dried. Mercury concentration was determined in so prepared material (eggs, feathers, guano, fish) by atomic absorption spectrophotometry with AMA-254 automatic mercury analyzer. Quality control has been carried out by the measurement of certified reference materials (QTM057 and QTM055BT), with RSD equal to $5 \%$ of the mean. Detection limit, given as three times the value of standard deviation of the blank equaled $0.06 \mathrm{ngHg} \cdot \mathrm{g}^{-1} \mathrm{~d} . \mathrm{w}$. Total mercury concentration was expressed in $\mu \mathrm{g} \cdot \mathrm{g}^{-1}$ dry weight. For each sample concentration on total mercury was analyzed three times and averaged.

\section{Results and Discussion}

In whole herring $(n=42)$ that were penguins feed the total mercury concentrations were in range from 7.35 to 69.28 $\mathrm{ng} \bullet \mathrm{g}^{-1} \mathrm{~d}$.w. The concentration of mercury in fish is mainly dependent on their size (age) and therefore it was estimated that in the whole fish with the lowest weight was $36.47 \mathrm{ng}$ of total mercury, while the fish with the highest weight was $4837.02 \mathrm{ng} \mathrm{Hg}$ (Kwaśniak et al., 2012).

In the guano collected from the catwalk, where 70 penguins resides, the average total mercury concentration was $139.18 \pm 115.28 \mathrm{ng} \bullet \mathrm{g}^{-1} \mathrm{~d} . \mathrm{w}$., and the range of $\mathrm{Hg}$

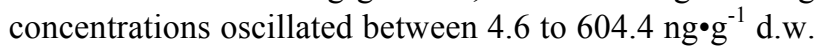
Into the penguins body by ingestion mostly organic mercury-methylmercury gets. It is absorbed through the intestinal wall, passed through the blood to all tissues and deployed in different cells (Wiener et al., 2003).

The concentrations of total mercury in the feathers of penguin characterized by relatively high variability in the range from 157.23 to $2545.55 \mathrm{ngHg}^{\circ} \mathrm{g}^{-1} \mathrm{~d}$.w. The results have also identified that the concentration of mercury in the feathers of penguins depend on the age of birds (Fig. 1).

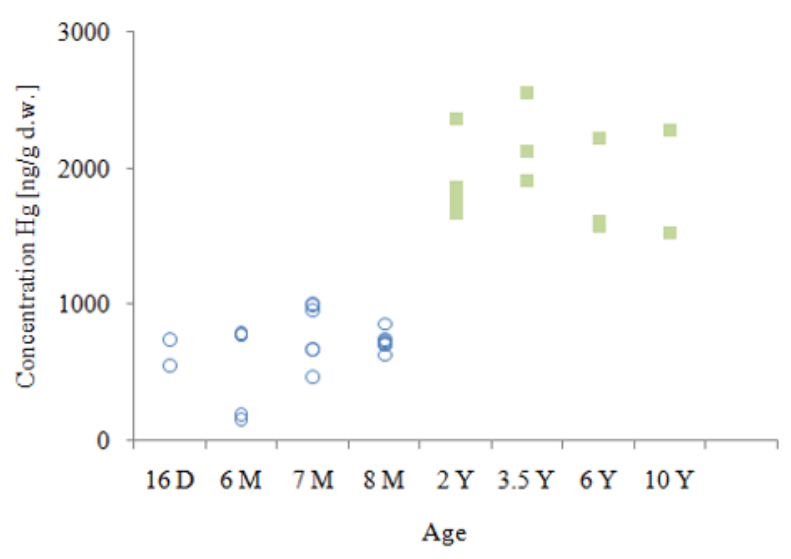

Fig. 1. The relationship between the concentration of mercury in the feathers and the age of penguins living in the ZOO. D-day, M-month, Y-year

In juveniles, less than 1 year of age, the concentration of mercury was twice lower than in adults, and was $775 \mathrm{ngHg} \cdot \mathrm{g}^{-1} \mathrm{~d} . \mathrm{w}$. In both groups, the concentrations of mercury slightly fluctuated. Elimination of xenobiotics from birds body by the feathers is held in the period of feather creation. As suggested by Furness and Camphuysen (1997) feathers only during growth reflect the level of xenobiotics in the blood of the bird. During moulting, penguins eat food in very small quantities that suggests that the mercury delivered to feathers come from the internal organs where it had been previously accumulated. In the literature, it is described that age does not affect the concentration of mercury in feathers of adult birds and an increase $[\mathrm{Hg}]$ in relation to chicks is indicated (Furness et al., 1995; Stewart et al., 1997). The hypothesis presented in the work of Thompson and Furness (1989) and Kim et al., (1996) which suggests that the ability of demethylation of organic mercury in the liver of birds depends on their age may explain the results. Chicks and juveniles penguins through demethylation may protect their body against methylmercury accumulated in the liver more effectively than adults.

The changes of mercury in the body of female birds are influenced by deposition of mercury to the forming egg. In 22 eggs from two broods the total mercury concentration was determined as the sum of the protein and the yolk and separately where possible from each other. Nearly ten times higher concentrations of $\mathrm{Hg}$ in the protein than in the yolk was found in eggs from hatching in autumn with values 0.65 and $0.06 \mathrm{ngHg}^{-1} \mathrm{~d}$.w respectively. The average concentration of mercury in eggs from the two broods (spring and autumn) was 0.95 ngHg $\bullet^{-1}$ d.w. The female penguin in the $\mathrm{ZOO}$ has usually two broods, and lays one to two eggs. Based on the results it can be stated that during this process from a female body to one egg from 5.1 to $17.8 \mathrm{mg} \mathrm{Hg}$ is eliminated. Four eggs in a year may result in removal of no more than $5 \%$ of the mercury coming from food. Thus, a deposition of mercury to eggs is not a significant way of detoxification of penguins.

In a guano randomly collected from the catwalk of penguins, the average total mercury concentration was $139.18 \pm 115.28 \mathrm{ngHg} \cdot \mathrm{g}^{-1} \mathrm{~d} . \mathrm{w}$. The lowest determined

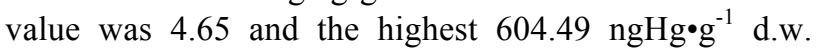
These results can be explained by two facts. The penguins feed was characterized by the high range of concentrations of $\mathrm{Hg}$ and that samples of guano came from individuals in different physical condition and age. Studies on the living and the dead birds allowed to assign the total mercury concentrations in guano to an individual of known age (Tab.1).

Guano of three-day chicks had the highest concentration of mercury in comparison with other samples of guano. However in 6 samples of 84 from the catwalk very similar levels of mercury in guano were reported but they came from unidentified individuals. Guano is a form of detoxification that includes mainly inorganic mercury. Mercury concentrations determined guano were sometimes two orders of magnitude smaller than that indicated in the feathers. However. by guano a bird excretes daily low-dose xenobiotic while 
Table 1. Mercury concentration found in guano collected during dissection of dead bird or during blood collection from alive birds in the $\mathrm{ZOO}$ of Gdańsk in the period 12.2009 - 02.2011. D-day, M-month, Y-year

\begin{tabular}{cc}
\hline Hg $\left[\mathrm{ng} \cdot \mathrm{g}^{-1}\right]$ d.w. & Penguin age \\
\hline 478.40 & $3 \mathrm{D}$ \\
25.42 & $4 \mathrm{M}$ \\
50.68 & $6 \mathrm{M}$ \\
241.82 & $2 \mathrm{Y}$ \\
295.07 & $2 \mathrm{Y}$ \\
264.75 & $4 \mathrm{Y}$ \\
267.56 & $4 \mathrm{Y}$ \\
104.49 & $4 \mathrm{Y}$ \\
141.72 & $11 \mathrm{Y} \mathrm{4} \mathrm{M}$ \\
159.82 & $11 \mathrm{Y} 4 \mathrm{M}$ \\
\hline
\end{tabular}

- detoxification through the feathers takes place once a year. No statistically significant correlation between the concentration of $\mathrm{Hg}$ in the guano and the concentration of herring (the food for penguins) was found.

\section{Conclusion}

Homogeneous diet of penguins living in the $\mathrm{ZOO}$ results with their chronic exposure to low doses of mercury what is reflected in high concentrations of this metal in feathers.

Of all studied elements responsible for mercury detoxification from the penguin body least effective way to eliminate was with eggs. Although eggs eliminate small portion of toxic mercury from the female body it is passed to the embryo and then to the chick. The results allow to identify the risks to breeding success due to the presence of mercury in eggs.

\section{Acknowledgements}

This paper was prepared with financial support from the Ministry of Science and Higher Education under the research project No. NN304 161637.

\section{References}

Furness, R.W., Camphuysen, K., 1997. Seabirds as monitors of the marine environment. Journal of Marine Science. 54: 726-737.

Kim, E.Y., Ichihashi, H., Saeki, K., Atrashkevich, G., Tanabe, S., Tatsukawa, R., 1996. Metal accumulation in tissues of seabird from Chaun, Northeast Siberia, Russia. Environmental Pollution, 92: 247-252.

Kwaśniak, J., Falkowska, L., Kwaśniak, M., 2012. The assessment of organic mercury in Baltic fish by use of an in vitro digestion model. Food Chemistry 132: 752-758.

Stewart, F.M., Philips, R.A., Carty, P., Furness, R.W., 1997. Influence of species, age, and diet on mercury concentrations in Shetland seabirds. Marine Ecology Progress Series. 151: 237-244.

Thompson, D.R., Furness, R.W., 1989. Comparison of the levels of total and organic mercury in seabird feathers. Marine Pollution Bulletin. 20: 577-579.

Wiener, J.G., Krabbenhoft, D.P., Heinz, G.H., Scheuhammer, A.M., 2003. Ecotoxicology of mercury. In: Hoffman, D.J., Rattner, B.A., Burton, G.A., Cairns, J., editors. Handbook of ecotoxicology. Boca Raton7 Lewis Publishing;. 409-463. 